\title{
LIBERDADE E PRESCIÊNCIA EM OCKHAM
}

José C. Estêvão*

SÍNTESE - Nos escritos políticos de Guilherme de Ockham surge com insistência a noção de liberdade, usada como argumento contra o absolutismo pontificio. A raiz deste conceito encontra-se, porém, nas obras filosófico-teológicas, onde, ao tratar do conhecimento divino dos futuros contingentes, o autor afirma que existe uma oposição entre o que afirma a filosofia e o que afirma a teologia a respeito.

PALAVRAS-CHAVE - Guilherme de Ockham. Liberdade. Conhecimento divino. Futuros contingentes.
ABSTRACT - The conception of liberty emerges throughout William of Ockham's political writings as an argument against pontifical absolutism. The roots of this concept are to be found, however, in his philosophical-theological works, where he deals with the divine knowledge of future contigents and draws an opposition between a theological and a philosophical undersatanding of the issue.

KEY WORDS - Ockham. Liberty. Divine knowledge. Future contingente.

Nos escritos de Guilherme de Ockham ocorre um uso inusitado, a seu tempo, da noção de liberdade. Como diz Lagarde, "a originalidade [de Ockham] sobre todos seus predecessores foi haver invocado um novo slogan para opor-se às investidas do espiritual sobre o temporal: o da liberdade cristã". A plenitude de poder que se arrogava o papado seria a negação de toda forma de liberdade, e o Autor entende que o cristianismo é a "lei da perfeita liberdade". ${ }^{2}$ Tal formulação é, talvez, o melhor achado retórico de Ockham. É utilizada pela primeira vez no Trac-

* Professor do Departamento de Filosofia da Universidade de São Paulo - USP. Este texto foi discutido com colegas do Centro de Estudos de Filosofia Patristica e Medieval de São Paulo (CEPAME), aos quais agradeço.

LAGARDE, G. DE, La naissance de l'esprit laïque au déclin du moyen âge. IV. Guillaume d'Ockham: Défense de l'Empire. Louvain, Nauwelaerts/Paris, Béatrice-Nauwelaerts, 1962; p. 85-86 (ênfase do Autor). Também BAUDRY ("Préface" in Breviloquium de Potestate Papae. Édition critique par L. Baudry. Paris, Vrin, 1937, p. VI): "Cette idée ne se rencontre, à notre connaissance, dans aucune des œuvres de Michel de Cézène ou de Bonagratia de Bergame". Tampouco MARsiLJO DE PÁDUA, no Defensor pacis, se preocupa com a questão; como lembra Miethke, seu grande tratado "was meant to be a defence of peace, of pax et tranquillitas, and nqt a defence of freedom". MIETHKE, J., "Lordship and Freedom in the Political Theory of the Early 14 Century", Veritas, 1995, 40, p. 688.

2 "Nam lex evangelica non majoris sed minoris servitutis est quam fuerit lex mosaica. Unde et lex perfectissime libertatis a beato Jacobo appellatur, [...]" (Breviloquium, II, c. 3, p. 19).

\begin{tabular}{|l|l|l|l|l|l|}
\hline VERITAS & Porto Alegre & v. 45 & n. 3 & Setembro 2000 & p. $369-380$ \\
\hline
\end{tabular}


tatus contra Benedictum (c. 1337-38) e torna-se recorrente desde então. ${ }^{3}$ A fórmula, no entanto, não era nova. Novo foi o modo como Ockham a utilizou, ou antes, a concepção de liberdade que subjaz à expressão (como diria ele: aquilo pelo qual "supõe" o termo liberdade...).

Se a expressão acabada da defesa da liberdade cristã só amadurece nas obras teológico-políticas, o tema é recorrente em toda sua obra filosófica e teológica. Embora os comentários do Organon e a Suma de Toda Lógica enfeixem a exposição sistemática da lógica, Ockham entendeu que devia acrescentar a este conjunto um texto sui generis, estranho à tradição deste repertório e que, no entanto, integra-se a ele harmonicamente: o Tratado da Predestinação e da Presciência de Deus com Respeito aos Futuros Contingentes. ${ }^{4} \mathrm{O}$ problema é teológico, mas a impostação assumida, desde o título, faz com que apareça como a mais "lógica" das questões teológicas.

É neste Tratado que Ockham se pergunta explicitamente: "mas de que modo se preservará a contingência da vontade com respeito àquilo que ela quer?". ${ }^{5}$ Ora, "contingência da vontade criada" é a expressão pela qual se poderia traduzir "liberdade", uma vez que, como indica Ghisalberti, ${ }^{6}$ o termo deve ser entendido, primariamente, como "vontade" e, secundariamente, como contingência da vontade na ação, além do que, para Ockham, "liberdade é certa indiferença e contingência, e distingue-se em oposição ao princípio ativo natural" ?

O Tratado da Predestinação assume nove "suposições": ${ }^{8}$ três delas (1 ${ }^{\mathbf{a}}, 7^{\mathrm{a}}$ e $\left.9^{\mathrm{a}}\right)$ são, digamos, "semânticas", referem-se à definição de termos ("predestinação",

3 "[...], secundum scripturam lex Christiana est libertatis, et maioris libertatis quam fuerit lex vetus." Tractatus contra Benedictum in GULLELMI DE OCKHAM Opera Politica III. Accuraverunt R. F. Bennett \& H. S. Offler. Mancunii e Typis Universitatis (Manchester, University Press), 1956; IV, c. 12, p. 262. Também, entre outras passagens, nas Octo Quæstiones de Potestate Papæ in Opera Politica I, q. I, c. 6, p. 29. E no Dialogus in GoldAST, M., Monarchia S. Romani Imperii. Frankfurt, 1614 [Graz, Akademischen Verlag, 1960]. T. II, III-I, 1, c. 7, p. 777.

4 Tractatus de prædestinatione et de præscientia Dei respectu futurorum contingentium in Opera Philosophica, II. Ed. P. Boehner \& S. Brown. Cura Instituti Franciscani, Universitatis S. Bonaventurae, St. Bonaventure, N.Y., 1978; q. III, p. 536. Cito segundo a tradução de Moacyr Novaes: Tratado da Predestinação e da Presciência de Deus com Respeito aos Futuros Contingentes. CEPAME, inédito, 1993.

5 "Sed quomodo tunc salvabitur contingentia voluntatis respectu voliti ab ea?" Op. cit., q. III, p. 536/21 (cito a paginação da edição de Boehner e Brown seguida da tradução de Novaes).

GHISALBERTI, A., "Amore di Dio e non-contraddizione: l'essere e il bene in Guglielmo di Ockham" in Filosofia e Teologia nel Trecento. Studi in ricordo di Eugenio Randi. Louvain-La-Neuve, Fédération Internationale des Instituts d'Études Médiévales, 1994, p. 65-66.

7 " $[\ldots]$ et sic libertas est quaedam indifferentia et contingentia, et distinguitur contra principium activum naturale", GUILLELMI DE OCKHAM Scriptum in librum primum Sententiarum (Ordinatio) (Prologus et Distinctio Prima). In Opera Theologica I. Ed. G. Gál, adlab. S. Brown. Cura Instituti Franciscani, Universitatis S. Bonaventuræ, St. Bonaventure, N.Y., 1967; d. I, q. 6, p. 501.

8 O uso do termo suppositio neste contexto dá a impressão de corresponder antes à acepção de "assunção" ou "pressuposto". Adams e Kretzmann, em sua tradução, preferiram usar assumptio (WILLIAM OCKHAM, Predestination, God's Foreknowledge, and Future Contingents. Trasl. M. Mc. Adams \& N. Kretzmann. Indianapolis, Hackett Publishing, $1983^{2}$, passim). Ockham usa a expressão ex suppositione como oposta a absoluta: "Et causa est quia quantumcumque sit vera vel fuerit vera ex suppositione, tamem possibile est quod non sit et quod numquam fuent vera absolute" (Tractatus de Praedestinatione, q. I, p. 511/4). No entanto, deve-se notar que as "suposiçōes" só são apre- 
"saber", "causa"); quatro (2ª $\left.3^{\mathrm{a}}, 4^{\mathrm{a}}, 8^{\mathrm{a}}\right)$ são "sintáticas": lembram o estabelecimento de regras proposicionais. As duas outras $\left(5^{\mathrm{a}}\right.$ e $\left.6^{\mathrm{a}}\right)$, apresentadas de modo provocativamente aporético, indicam que a razão e a fé se opõem no que diz respeito à atribuição de verdade das proposições de futuro contingente. São as que nos interessam particularmente aqui:

"Quinta suposição: Segundo o entendimento do Filósofo não apenas nos contingentes futuros, mas também no que diz respeito ao presente e ao passado que equivale ao que diz respeito ao futuro, Deus não conhece um lado da contradição mais do que o outro; pelo contrário, nenhum dos dois, segundo ele, é conhecido por Deus, pois segundo ele, Segundos Analiticos I, não é conhecido senão o verdadeiro. Mas nestes a verdade não está determinada, pois segundo ele não se pode aduzir nenhuma razão por que um lado seja mais verdadeiro do que o outro, e assim, ou ambos são verdadeiros ou nenhum; mas não é possível que cada um seja verdadeiro, portanto nenhum é (verdadeiro), logo nenhum é conhecido.

Sexta suposição: Deve-se sustentar sem dúvida que Deus conhece certeiramente todos os contingentes futuros; que certeiramente conhece que lado da contradição será verdadeiro e que lado será falso; deste modo porém, que todas as proposições tais como 'Deus conhece que este lado da contradição é verdadeiro' ou 'aquele' são contingentes e não necessárias, como antes foi dito. Mas é difícil ver de que modo sabe isto, uma vez que um lado não é determinado para a verdade mais do que o outro." ${ }^{9}$

A 5 a suposição enuncia, de maneira resumida, as conclusões da Expositio in Perihermenias, capítulo IX. Onde, uma vez determinada a compreensão do texto, pareceu conveniente ao comentador indicar a verdade. Não só Aristóteles entende que a verdade das proposições de futuro contingente é indeterminada, como também decorre de sua posição que Deus tampouco conhece a verdade das partes contraditórias nas proposições de futuro contingente. Isto porque conhecer é conhecer a verdade, ora, se nenhuma das partes é verdadeira, nenhuma pode ser

sentadas após a resolução da I Questão, isto é, depois de demonstrado que a predestinação e a presciência passivas não são reais. Veja-se a resposta à $5^{\mathbf{a}}$ objeção (I Questão), onde Ockham distingue o "imutável real" (que é necessário) e o "imutável complexo" (isto é, a proposição), que não é: "Et cum dicitur 'praedestinatio divina est immutabilis, igitur necessania omnino', dico quod immutabile reale est necessarium. Sed loquendo de immutabile complexo, [...], sic non omne immutabile est necessarium,[...]" (Tractatus de Praedestinatione, q. I, pp. 511/4). Vale dizer, as dúvidas que são resolvidas com o socorro dos "pressupostos" listados decorrem de um mau uso dos termos e das propriedades das proposições.

9 "Quinta suppositio: quod secundum intentionem Philosophi non solum in futuris contingentibus, immo etiam in illis de praesenti et de praeterito quae aequivalent illis de futuro, Deus non plus scit unam partem contradictionis quam aliam, immo neutra secundum eum est scita a Deo, quia secundum eum, I Posteriorum [c. 1 (71b 19-26)], nihil scitur nisi verum. Sed in illis non est veritas determinata, quia secundum eum nulla ratio potest assignari quare magis una pars sit vera quam alia, et ita vel utraque pars erit vera vel neutra; sed non est possibile quod utraque pars sit vera, ergo neutra, et igitur neutra scitur. Sexta suppositio: quod indubitanter est tenendum quod Deus certitudinaliter scit omnia futura contingentia, ita quod certitudinaliter scit quae pars contradictionis erit vera et quae falsa, ita tamen quod omnes tales propositiones 'Deus scit hanc partem contradictionis esse veram' vel 'illam' sunt contingentes et non necessarie, sicut prius dictum est. Sed difficile est videre quomodo haec scit, cum una pars non plus determinetur ad veritatem quam alia" (Tractatus de Praedestinatione, q. I, p. 516-517). 
conhecida. ${ }^{10}$ No entanto, como também afirma a $6^{\mathrm{a}}$ suposição, "de acordo com a verdade e os teólogos", Deus conhece determinadamente uma das partes das proposições de futuro contingente."

Só após haver mostrado que o problema tem como âmbito próprio as proposições e não corresponde a nada de real - o que é feito na I Questão - e haver lembrado esta série de regras sintáticas e semânticas, é possível, então, esclarecer que ciência tem Deus a respeito dos futuros contingentes (ПI Questão), isto é, que "tem notícia determinada, certa, infalível, imutável e necessária com respeito a uma parte da contradição" das proposições de futuro contingente. ${ }^{12}$ Ao mesmo tempo, é possível "provar que o predestinado pode ser condenado" (Questões III-V), ou seja, que se preserva a contingência tanto da vontade dos homens, quanto da de Deus. ${ }^{13}$

O $1^{\circ}$ Artigo da II Questão inicia-se com a exposição das razões pelas quais não se pode admitir que Deus tenha um conhecimento determinado do futuro contingente:

"Em primeiro lugar, porque nos futuros contingentes não é determinada nem a verdade nem a falsidade, portanto etc. Em segundo lugar: se fosse, quer deliberássemos ou não, necessariamente aconteceria o que é assim conhecido por Deus, e conseqüentemente em vão deliberaríamos ou negociariamos. Em terceiro lugar: se fosse, Deus teria um poder limitado. Prova: porque se Deus pode fazer determinadamente algo de modo que não o seu oposto, tem um poder determinado e limitado; assim, de maneira similar etc. Em quarto lugar: o que não é verdadeiro em si, não é conhecido por Deus segundo uma notícia determinada; ora, o futuro contingente é deste modo; logo, etc. Ad oppositum est fides." ${ }^{14}$

Reencontramos todo o elenco de objeções racionais que se pode fazer ao conhecimento da verdade das proposições de futuro contingente, ou antes, que se pode fazer ao conhecimento humano acerca destas proposições. Aqui, no entanto, disputa-se apenas acerca do conhecimento divino.

10 "Et ideo diceret Philosophus quod etiam Deus non plus scit unam partem contradictionis quam aliam; immo neutra scitur a Deo, quia ex quo neutra pars est vera, sicut hicdeterminat, et secundum eum, I Posteriorum [I, c. 1 (71b 20-27)], nihil scitur nisi verum, sequitur quod neutra pars est scita" (Expositio in Librum Perihermenias Aristotelis in Opera Philosophica, II. Ed. A. Gambatese \& S. Brown. I, c. 6, p. 421-422).

11 "Tamen secundum veritatem et theologos aliter est dicendum, quia dicendum est quod Deus determinate scit alteram partem" (Expositio in Perihermenias, I, c. 6, p. 422).

12 "Utrum Deus respectu omnium futurorum contingentium habeat notitiam determinatam, certam, infallibilem, immutabilem et necessariam respectu unius partis contradictionis" (Tractatus de Praedestinatione, q. II, p. 520/10).

13 "Sed quomodo tunc salvabitur contingentia voluntatis respectu voliti ab ea? Respondeoquod voluntas Dei ad extra et voluntas creata in illo instanti in quo agit contingenter agit" (Op. cit., q. III, p. 536/21).

"Et primo, quod non determinatam: Quia in futuris contingentibus non est determinata veritas nec falsitas, ergo etc. Secundo: si sic, sive consiliaremur sive non, necessario eveniret quod sic a Deo est congnitum, et per consequens frustra consiliaremur vel negotiaremur. Tertio sic: si sic, Deus esset limitatae potentiae. Probatio: quia si Deus potest facere determinate hoc ita quod non suum oppositum, est determinatae et limitatae potentiae; igitur similiter etc. Quarto: quod non est in se verum, non scitur a Deo notitia determinata; sed futurum contingens est huiusmodi; igitur etc. Ad opositum est fides" (Op. cit., q. II, a. 1, p. 520/10). 
Note-se que Ockham não apresenta nenhum argumento ou autoridade em defesa da tese, salvo a fé. Não porque não poderia ser produzido ou aduzida, mas porque lhes parecem falsos. Não há nenhuma referência à solução tradicional (de Boécio a Tomás), invocando a eternidade de Deus. ${ }^{15}$

Fernando Fleck resume de modo sucinto e correto a tradição patrísticomedieval anterior a Ockham:

"A atitude de considerar o problema dos futuros contingentes um problema aparente é a dominante na Idade Média, quando a questão foi tratada principalmente do ponto de vista epistêmico-teológico: admitida, por um lado, a presciência divina como abrangendo todos os eventos futuros, e, por outro lado, a liberdade humana como fonte de contingência, surge a questão de mostrar a compatibilidade entre ambas. Um marco na história do problema é a discussão por Boécio em De Consolatione Philosophiæ, V. Esta obra, a tradução e os dois comentários de Boécio a De Interpretatione, bem como De Civitate Dei, V, 9, de Santo Agostinho foram as principais fontes da escolástica medieval na questão. A solução clássica na Idade Média é a de Sto. Tomás, inspirada em Boécio: embora não possa haver ciência do futuro em matéria contingente (já que os enunciados em tal matéria não são definidamente verdadeiros ou falsos), Deus, sendo eterno, isto é, não estando submetido ao tempo, conhece o valor-de-verdade destes enunciados não enquanto futuros, mas enquanto 'presentes' à sua eternidade. Rigorosamente, portanto, não se trata de presciência divina - esta seria temporal e impossível - mas de ciência eterna (atemporal). (Cf., por exemplo, In Perihermeneias, lect. XIII-XV; De Veritate, q. 2, a. 12; Summa Teologicæ, I, q. 14, a. 13). A solução de Sto. Tomás foi criticada por Scotus como implicando, entre outras coisas, a contradição de que Deus, coexistindo com o futuro, coexistiria com o que não existe (Ordinatio, I, dd. 38-39, Opera Omnia, VI, pp. 109-111). A solução do próprio Scotus, de que Deus conhece o futuro, conhecendo sua vontade, que é contingente e, assim, fonte de toda contingência, parece, porém, reduzir em última instância o agente humano a mero instrumento da vontade divina. ${ }^{16}$

Como mostra Adams, ${ }^{17}$ a crítica desta posição fora feita por Duns Scot, entendendo que o tempo existe apenas como presente atual e para quem é contraditório afirmar simultaneamente que "todo o fluxo do tempo e tudo o que é no tempo está presente na eternidade" e que "na eternidade de Deus estão presentes todos os tempos". Para que a eternidade de Deus tenha presentes as coisas em sua existência, elas devem ser "absolutamente atuais"; ora, só as coisas temporalmente presentes são "absolutamente atuais"; logo só podem ser presentes se forem "absolutamente atuais" agora; mas então decorre que, como o que é atual num certo tempo não pode ser produzido na atualidade pela primeira vez no tempo posterior, se na eternidade de Deus estão presentes todas as coisas, nada pode ser produzido em atualidade no futuro - o que é absurdo. Ou, se algumas coisas serão

$15 \mathrm{Na}$ Ordinatio Ockham é explícito: "et hoc non esset, quia futura contingentia essent sibi praesentia, nec per ideas tamquam rationes cognoscendi, [...]" (Ordinatio I, d. 38, q. única, p. 585).

FLECK, F. P. A., O Problema dos Futuros Contingentes. Porto Alegre: UFRGs, 1991, p. 3-4. Para um tratamento particularmente interessante do problema em Agostinho, cf. NOVAES, M., O livre-arbitrio

ADAMS, M. MC., William Ockham. Notre-Dame: University of Notre-Dame Press, 1987, p. 1122. 
produzidas na atualidade pela primeira vez no tempo posterior, então se na eternidade de Deus estão presentes todas as coisas, algumas coisas serão produzidas em atualidade duas vezes - o que é absurdo. ${ }^{18}$ Duns Scot concede que se a totalidade do tempo existisse simultaneamente, estaria presente para a eternidade, mas a totalidade do tempo teria que existir num único e mesmo tempo, o que é absurdo.

Embora, aqui, Ockham o acompanhe, sem julgar necessário explicitar a adesão, já na apresentação da $6^{\mathrm{a}}$ suppositio, recusa a solução de compromisso proposta por Duns Scot, segundo a qual o intelecto divino, "de algum modo precedendo a determinação da vontade divina", apreende as proposições complexas como neutras e é a vontade divina que determina qual será verdadeira, de modo que conhece como verdadeira aquela que quer que seja verdadeira. ${ }^{19}$ Solução a ser retificada porque elimina a contingência da "vontade criada": se a vontade criada é determinada pela vontade incriada, "agirá tal como o fogo, e assim se eliminam o mérito e o demérito"; se não é, não basta a vontade divina ${ }^{20}$ É necessário modalizar: "Deus quer que uma parte seja verdadeira e a outra falsa. Todavia, quer contingentemente". ${ }^{21}$

No entanto, como vimos, num certo sentido, as proposições de futuro contingentes são verdadeiras ou falsas, embora então já não sejam de futuro, mas, Ockham insiste nisso, permanecendo contingentes. Como só existe aquilo que é em ato e os termos destas proposições supõem pelo que não é em ato, não podem ser nem verdadeiras nem falsas; mas no tempo em que se cumprirem, então serão determinadamente verdadeiras, mas poderiam não ser nem nunca ter sido verdadeiras (ou, vice-versa, falsas). A questão centra-se na determinação e certeza acerca de qual futuro será. O problema é como se obtém o conhecimento - sendo indiferente se de coisas passadas, presentes ou futuras: "é impossivel exprimir

${ }_{18}$ A Autora nos remete para DuNs scor, Ordinatio, I, d. 38, q. 2 e d. 39, qq. 1-5. Não é relevante para nosso objetivo discutir que "Aquinas would reply that Scotus's criticism misunderstands his positio", como faz, com razão, Adams (op. cit., p. 1123).

19

"Et dicit Doctor Subtilis[Reportatio, I, d. 38, q. 2, n. 3] quod intellectus divinus, prout quodammodo praecedit determinationem voluntatis divinae, apprehendit illa complexa ut neutra, et voluntas determinat alteram partem esse veram pro aliquo instanti, volens alteram partem esse veram pro eodem instanti" (Tractatus de Praedestinatione, q. I, p. 516/7).

"Sed contra istam opinione: quia non videtur salvare certitudinem scientiae Dei respectu futurorum quae simpliciter dependent a voluntate creata; quia quaero, utrum illam determinationem voluntatis divinae necessario sequatur determinatio voluntatis creatae aut non. Si sic, igitur voluntas necessario ageret sicut ignis, et ita tollitur meritum e demeritum. Si non, igitur ad sciendum determinate alteram partem contradictionis illorum requiritur determinatio voluntatis creatae, quia determinatio voluntatis increatae non sufficit, cum voluntas creata possit in oppositum illius determinationis" (Op. cit., q. I., p. 517/7). "Dico: quod una pars nunc determinate est vera, ita quod non falsa, quia Deus vult unam partem esse veram et aliam esse falsam. Tamen contingenter vult, [...]" (Op. cit., p. 518/8),

Craing nota que "The 'obtains' here it tenseless, and key to Ockham position is the view that the notion of determinacy in unrelated to the question of whether the state of affairs is past, present, or future" (CRAING; W. L., The Problem of Divine Foreknowledge and Future Contingents from Aristotle to Suarez. Leinden, Brill, 1988, p. 149). A possibilidade do conhecimento de unreal entities sustentada por Adams (cf., por exemplo, William Ockham, op. cit., p. 401 ss.) foi geralmente rejeitada pelos comentadores: Cf. KARGER, E. C., A Study in William of Ockham's Modal Logic. University of 
com clareza o modo pelo qual Deus sabe os futuros contingentes", mas nada impede de conceder (ou seja, não implica nenhuma contradição em si) que "a essência divina é uma notícia intuitiva tão perfeita, tão clara, que ela é notícia evidente de todos os passados e futuros, de tal forma que sabe que parte da contradição será verdadeira e que parte falsa". ${ }^{23}$

Ockham afirma e reafirma que as proposições de futuro contingentes são determinadamente verdadeiras ou falsas. Mas exclusivamente pela fé. $\mathrm{O}$ texto mais enfático a respeito é o da Ordinatio: "Deus conhece evidentemente todos os futuros contingentes. Mas não sei dizer de que modo (sed modum exprimere nescio)" e, mais adiante: "pela nossa razão natural possivel e a priori não se pode provar esta conclusão, mas pela autoridade da Bíblia e dos Santos". ${ }^{24}$

Contudo, pressuposto o dado revelado, pode-se mostrar que não se verificam as incompatibilidades que decorrem da mesma assunção quanto ao conhecimento de que dispõem os homens no estado presente. Não se trata de mostrar que os princípios revelados podem ser, em alguma medida, "fundamentados" pela ausência de contradição - deve-se advertir explicitamente contra tal pretensão ${ }^{25}$ - mas tão só de estabelecer com correção as conseqüências dos princípios admitidos pela fé.

Para Ockham, aos argumentos citados acima inferem conseqüências indevidas do princípio de que Deus tem um conhecimento determinado dos futuros contingentes: ad primum: a fé; ad secundum: não se nega a deliberação; pois ainda que Deus "conheça determinadamente uma parte, ainda assim conhece contingentemente e pode não saber e podia não saber", donde, independentemente deste conhecimento, é possivel deliberar. Note-se: Deus conhece "contingentemente", "pode não saber" e "podia não saber", traços que tendem a parecer incompatíveis com a onisciência divina, mas cujo sentido é

California, 1976, p. 196 ss. Também FREDDoso, A. J., "Introduction" in Ockham's Theory of the Propositions. Part II of the Summa Logicæ. Transl. by A. J. Freddoso \& H. Schurman. Notre Dame / London, University of Notre Dame Press, 1980; p. 37 ss.

23 "Ideo dico quod impossibile est clare exprimere modum quo Deus scit futura contingentia. [...]. [...] potest concedi quod essentia divina est notitia intuitiva quae est tam perfecta, tam clara quod ipsa est notitia evidens omnium praeteritorum et futurorum, ita quod ipsa scit quae pars contradictionis erit vera quae pars falsa" (Tractatus de Praedestinatione, q. I, p. 517-518/8).

"[...], quod Deus evidenter cognoscit omnia futura contingentia. Sed modum exprimere nescio. [...]. Ista conclusio, quamvis per rationem naturalem nobis possibilem et a priori probari non possit, tamen per auctoritates Bibliae et Santorum, quae sunt satis notae, potest probari" (Ordinatio, IV, d. 38 , q. única, p. 584-585. "Is there any solution of this problem? Ockham confesses in the Comentary on the Sentences: Sed modum exprimere nescio. The solution of this problem escapes the limites of a human understanding" (BOEHNER, P., Collected Articles on Ockham. Ed. E. M. Buytaert. St. Bonaventure, N.Y., The Franciscan Institute, 1992, p. 440).

GUELLUY (Philosophie et théologie chez Guillaume d'Ockham. Louvain, Nauwelarerts / Paris, Vrin, 1947, pp. 245/249) lembra que, embora conceba a teologia como tendo o papel de esclarecer as ligações de proposições, Ockham é enfático em afirmar que não se chega ao conhecimento evidente dos mistérios revelados provando que não comportam nenhuma contradição: "Ad aliud dico quod illud scitur evidenter de quo scitur evidenter quod ad ipsum non sequitur impossibile. Hoc autem non scitur in propositio de aliqua propositione credibile. Unde non scitur evidenter quod credibile non est antecedens in consequentia in qua infertur impossibile. Et quando dicitur quod omne argumentum peccat in materia vel in forma, concedo, quamvis hoc non possit scire evidenter" (Ordinatio I, Prol., q. 7, p. 201). 

seguintes. Ad tertium: o conhecimento determinado mas contingente afirma a potência divina, ao contrário de implicar em limitação, pois Deus não está obrigado à determinação. Ad quartum: pode ser conhecida como tal a proposição contingente, pois "também é verdadeira a proposição que é contingentemente verdadeira" ${ }^{26}$

Tal conhecimento é "certo e infalível" e daí não decorre que Deus se engane ou possa se enganar. No entanto, pode-se argumentar que se "soube que estarei sentado amanhã, e não estarei sentado amanhã, portanto se engana": acredita ser na coisa o que não é na coisa. De modo semelhante, se "soube que estarei sentado amanhã, e é possível que eu esteja sentado amanhã, então pode se enganar", isso porque como de "duas proposições assertóricas segue-se uma conseqüência assertórica, igualmente a uma proposição assertórica e outra do possível, segue-se uma conclusão do possível". ${ }^{27}$

A resposta é exemplar do método de trabalho de Ockham: os argumentos são logicamente incorretos. A primeira conseqüência seria verdadeira se ambas as

26 "Ad secundum: prima consequentia non valet, quia licet determinate sciat unam partem, tamen contingenter scit et potest non scire et potuit numquam scivisse, et ideo expedit consiliari. Ad tertium: nego consequentiam. Ad probatione dico quod verum est: si Deus ita causaret unam partem contradictionis quod non posset causare illam, tunc esset limitatae potentiae. Ad quarturn patet quod minor est falsa. Sic tamen est vera quod est contingenter vera, quia potest esse falsa, et potuit numquam fuisse vera" (Tractatus de Praedestinatione, q. II, a. 1, p. 521/11).

"Probatio, quia sequitur 'Deus novit me sessurum cras, et non sedebo cra, ergo decipitur'. Haec consequentia patet, quia credens illud esse in re quod non est in re decipitur, igitur a simili: 'Deus novit me sessurum cras, et possibile est me non sedere cras, igitur potest decipi'. Probatur haec secunda consequentia, quia sicut ad duas de inesse sequitur conclusio de inesse, ita ad unam de inesse et alia de possibili sequitur conclusio de possibili" (Op. cit., q. II, a. 2, p. 521-522/11). BAUDRY, L., Lexique philosophique de Guillaume de Ockham. Étude des notions fundamentales. Paris: Lethielleux, 1957, p. 218: "On distingue $1^{\circ}$ les propositions de inesse que ne comprennent pas de mode. 'Propositio de inesse est illa quae est sine modo' (Summa Logicæ, [II, c. 1, p. 242]). a) Elles sont dites simpliciter de inesse quand l'attribut convient toujours ou ne convient jamais au sujet. b) Elles sont de inesse ut nunc quand l'attribut peut être à un moment affirmé d'un sujet et à un autre moment nié du même sujet. "Illa [...] est de inesse simpliciter in qua non potest praedicatum competere subjecto in uno tempore et negari in alio, sed semper uniformiter se habet ita quod semper vere praedicatur vel numquam. Illa ... dicitur de inesse ut nunc in qua potest praedicatum uno tempore vere affirmari de subjecto et in alio tempore vere negari' (ib., [III-1, c. 31, p. 441])." A tradução de propositio de inesse por "assertónica" é utilizada por Adams e Kretzmann na tradução do Tractatus de Praedestinatione (op. cit., passim, cf. p. 36, n. 7), mas convém lembrar que a expressão de inesse mantém a assunção de inerência, como se vê no próprio texto deste tratado, infra, q. II, a. 4, p. 532: "Maior est de necessario, quia praedicatum necessario inest subiecto; et minor est de inesse simpliciter, quia est vera pro eternitate; igitur sequitur conclusio de necessario". Ao mesmo tempo, a Summa Logicæ (in Opera Philosophica I. Ed. P. Boehner, G. Gál \& S. Brown. Cura Instituti Franciscani, Universitatis S. Bonaventurae, St. Bonaventure, N.Y., 1974; c. 32, p. 94) lembra que esta inerência é de predicação e não deve ser confundida com inerência real: "Sicut autem praedicatum de subiecto, ita dicimus praedicatum esse in subiecto, et praedicatum convenire subiecto, et praedicatum inesse subiecto, et praedicatum inhaerere subiecto. Quae non sunt intelligenda ac si praedicatum poneretur realiter inhaerere subiecto, illo modo quo albedo inest parieti, sed omnia tali significant idem quod 'praedicari', nec aliter accipienda sunt nisi pro 'praedicari'. Et isto modo omnia accidentia, quae sunt novem praedicamenta, possunt dici esse in substantia sicut in subiecto, non quidem per realem inhaerentiam, secundum opinionem multorum, sed per praedicationem veram." 
premissas o fossem, mas não podem ser, pois se "Deus soube que estarei sentado amanhã" é verdadeira, e como conhecer é conhecer a verdade, então é verdade a proposição "eu estarei sentado amanhã" e a segunda premissa "eu não estarei sentado amanhã" é necessariamente falsa. Portanto, não se segue a conclusão "Deus se engana". ${ }^{28}$ A segunda conseqüência, construída à semelhança da primeira, tampouco é boa, uma vez que a inferência é inaceitável: a composição (mixtio) das duas proposições exige que a maior seja pura e simplesmente assertórica, sendo verdadeira se a proposição de modo possivel se verifica afirmativamente. ${ }^{29}$ Mas então, a conclusão é o oposto da pretendida: "Deus não se engana".

A formulação correta seria: da proposição "'Deus não pode se enganar, e é possível que eu não esteja sentado amanhã', segue-se apenas esta conclusão 'portanto Deus não sabe necessariamente que estarei sentado amanhã, mas apenas contingentemente'". Ou seja, a premissa maior do argumento não é, como parece, uma proposição assertórica, mas "meramente contingente, porque pode ser verdadeira, pode ser falsa e nunca ter sido verdadeira". ${ }^{30}$

Dada a acepção estrita de "conhecer" estabelecida na $7^{\mathrm{a}}$ suppositio - conhecer é saber a verdade - conhecer o que é contingente não implica mudança em Deus. As proposições de presente podem mudar de verdadeiras em falsas e viceversa, e Deus as conhece quando são verdadeiras e não as conhece quando não são verdadeiras, "sem nenhuma mudança sua, em razão da mudança apenas na criatura ou nas proposições conhecidas deste modo". ${ }^{31}$

Quanto às proposições de futuro, é preciso distinguir as que não implicam algo presente ou passado ("Sócrates estará sentado no instante a", afirmada antes do instante a) e as que, sendo futuras apenas literalmente (secundum vocem), implicam que coisas presentes ou passadas sejam futuras ("Sócrates estará sentado no instante a", afirmada depois do instante a). No primeiro caso, se Deus co-

${ }_{28}$ "Et ex illis duabus, si possent esse simul verae, sequitur conclusio. Sed non possunt esse simul verae, quia sequitur 'si Deus novit me' etc., igitur haec est vera 'ego sedebo cras', quia nihil scitur nisi verum. Igitur sua opposita est falsa, quia aliter contradictoria essent simul vera" (Tractatus de Praedestinatione, q. II, a. 2, p. 522/12).

29

"Sed quidquid sit de prima consequentia, secunda non valet, quia ad hoc quod talis mixtio valeret, oporteret quod maior esset de inesse simpliciter, ita quod semper esset necessario vera quantumcumque illa de possibili poneretur in esse. Et tunc sequitur conclusio de possibili, et aliter non" (Op. cit., q. II, a. 2, p. 522-523/11). A regra é exposta na Summa Logicæ, III-1, c. 34, p. 452: "Unde primo sciendum est quod si illa de possibili sumatur in sensu compositionis vel aequivalens ei, sive maior fuerit de possibili sive minor, non valet mixtio talis universaliter, quia contingit praemissas esse veras conclusione exsistente falsa. [...]. Sciendum est tamen quod si minor sit de inesse simpliciter sive maior, valet mixtio."

"[...], sic arguendo 'Deus non potest decipi, et possibile est me non sedere cras', sequitur tantum ista conclusio 'ergo Deus non necessario scit me sessurum cras sed tantum contingenter'. Igitur ad hoc quod prima mixtio valeat, oportet quod maior sit de inesse simpliciter. Sed patet quod non est, quia est mere contingens, quia potest esse vera et potest esse falsa e numquam fuisse vera" (Tractatus de Praedestinatione, op. cit., q. II, a. 2, p. 523/12).

"Dico quod loquendo de propositionibus mere de praesenti, quae nullo modo dependent a futuro, sic dico quod sicut tales possunt mutari de veritate in falsitatem et e converso, ita potest Deus tales aliquando scire et aliquando non, et scire illas postquam non scivit, et non scire postquam scivit, et scire aliquam propositionem quam prius non scivit, sine omni mutatione sui, propter solam mutationem in creatura vel in propositionibus talibus scitis, [... $]^{n}$ (Op. cit., q. II, a. 3, pp. 524/13). 
nhece antes do instante a que algo será verdade, então sempre conhecerá, pois uma proposição de futuro que fosse alguma vez conhecida como verdadeira sempre seria verdadeira. ${ }^{32}$

Mas no segundo caso, como se tomam coisas passadas ou presentes como sendo futuras, a proposição, que antes do instante a era verdadeira, passa a ser falsa (e vice-versa): “'Sócrates é predestinado' antes da beatitude sempre é verdadeira, se alguma vez for verdadeira, mas depois da beatitude sempre será falsa" ${ }^{33}$ (pois a coisa pela qual supõe a proposição já não está nem no passado nem no futuro, mas no presente); "e tal futuro contingente Deus pode não conhecer depois de ter conhecido sem nenhuma mudança de sua parte, em razão da mudança da coisa e da passagem do tempo". ${ }^{34}$

Tomemos apenas mais duas proposições de Ockham que nos interessam particularmente: Deus tem conhecimento necessário dos futuros contingentes no sentido em que se afirma que a própria essência divina é a única cognição necessária; mas por este conhecimento não se entende que os futuros, que são contingentes, sejam conhecidos como necessários, e sim tais como são, isto é, contingentes. ${ }^{35}$

Também não se pode afirmar que "tudo o que Deus sabe que será, necessariamente será; Deus sabe que a será amanhã; então a necessariamente será". Ora, a premissa maior é falsa, pois ou é tomada no sentido "da divisão", "e muitas coisas que Deus sabe que serão, serão contingentemente e não necessariamente, e por isso segue-se uma conclusão falsa", ${ }^{36}$ ou então é tomada no sentido "da composição",

32 "Sed loquendo de propositionibus de futuro, distinguo: quia quaedam sunt futura quae non important aliquod praesens vel praeteritum, et in talibus impossibile est quod Deus talia futura prius sciat et postea non sciat, quia impossibile est quod ante a instans Deus sciat istam 'Sortes sedebit in a' et postea nesciat eam. Et causa est quia ante a non potest primo esse vere e postea falsa; sed sit vera ante $a$, semper fuit vera ante $a$, quia omnis propositio simpliciter de futuro si sit semel vera semper fuit vera" (Op. cit., q. II, a. 3, p. 525/14).

33 'Sortes est praedestinatus' quia ante beatitudinem semper est vera, si semel sit vera, sed post beatitudinem semper enit falsa" (Op. cit., q. II, a. 3, p. 526/14).

34 "Quaedam sunt futura solum secundum vocem quae implicant ista propositio 'Sorte sedebit in a', quae implicat praeterita esse futura, scilicet quod a sit futurum et quod sessio sit futura. Et talis de futuro potest mutari de veritate in falsitatem, quia ante a fuit vera et post a est falsa; et tale futurum contingens potest Deus non scire postquam scivit sine omni mutatione ex parte sua, propter mutationem rei et trasitionem temporis" (Op. cit., q. II, a. 3, p. 525/14).

35 'Quia sequitur 'Deus scit a immutabiliter, igitur necessario'. Consequentia probatur, quia non ponitur in Deo nisi necessitas immutabilitatis, igitur quidquid est in eo immutabiliter, est in eo necessario. Dico quod hoc potest intellige dupliciter: uno modo, quod scientia Dei qua sciuntur futura contingentia sit necessaria. Et hoc est verum, quia ipsa essentia divina est unica cognitio necessaria et immutabilis omnium tam complexorum quam incomplexorum, necessariorum et contingentium. Secum modom quod per illam scientiam sciantur necessario futura contingentia. Et sic non est necessaria, nec debet concedi quod Deus habeat scientiam necessariam de futuris contingentibus sed potius contingentem, quia sicut hoc futurum contingens contingenter erit, ita Deus scit ipsum contingenter fore, quia potest non scire ipsum fore, si ipsum scit” (Op. cit., q. I, a. 4, p. 529530/17).

36 4[...]: omne scitum a Deo fore necessario erit; a est scitum a Deo fore; igitur a necessario erit. Maior est de necessario, quia praedicatum necessario inest subiecto; et minor est de inesse simpliciter, quia est vera pro aeternitate; igitur sequitur conclusio de necessario. Dico quod maior est falsa, quia exprimit sensum divisionis, et multa scita a Deo fore contingenter erunt et non necessario, et ideo sequitur conclusio falsa" (Op. cit., q. II, a. 4, p. 532/18). 
mas então a reunião das premissas não vale porque a menor é assertórica de presente..$^{\text {r7 }}$ Isto é, fere a regra estabelecida na $8^{\mathrm{a}}$ suposição.

Uma vez entendido como se atribui a Deus o conhecimento do contingente, pode-se, na Questão seguinte, a III, responder de que modo "se preservará a contingência da vontade com respeito às coisas por ela desejadas", afirmando, como vimos de início, que "a vontade de Deus ad extra e a vontade criada, no instante em que age, age contingentemente". Não no sentido de que a vontade possa, no mesmo instante, causar e não causar, mas que antes do instante a possa "livre e contingentemente causar ou não causar em a", e que, sem variação em si ou para outra coisa, possa se abster de causar depois de tal instante. ${ }^{38}$

Ainda que afirmada a presciência divina, a vontade causa livremente.

De que modo estes desenvolvimentos teológicos (em chave lógica) comprometem soluções (teológico-)políticas como aquelas a que nos referimos no início?

Tomemos, muito esquematicamente, um contra-exemplo entre os contemporâneos de Ockham: Dante, um dos que defendem que o poder temporal vem "da Fonte de toda autoridade" sem qualquer intermediário, ${ }^{39}$ sustenta ao mesmo tempo que é pela Divina Providência que o povo romano detém o Império. Pode-se conhecer a vontade de Deus pela razão e pela fé, e pela fé conhecem-se aqueles desígnios divinos que a razão não alcança. Estes podem ser revelados ou ocultos, isto é, os que não são conhecidos sequer pelas Escrituras. Tais juízos divinos ocultos são acessíveis, no entanto, por graça especial. Dentre os modos pelos quais se revela a vontade oculta por graça especial está o duelo, cujas regras, distintas do combate em geral, o Autor detalha. Ora, é por direito de duelo que os romanos constituem o Império e, portanto, dão a conhecer a vontade divina. ${ }^{40}$ Do mesmo modo, Grandes Eleitores imperiais são denuntiatores divinae providentia. ${ }^{4}$

A resposta de Ockham à questão sobre como e quando o Império Romano vem a ser um verdadeiro império é simples e significativa: "não sei dizer" ${ }^{42}$ Quan-

37 "Sed autem maior accipiatur in sensu compositionis, ita quod haec sit necessaria 'omne scitum a Deo [fore] erit', tunc mixtio non valet, quia minor est de inesse ut nunc, et ideo non sequitur conclusio" (Op. cit., q. II, a. 4, p. 532/18). Sobre a propositio de inesse ut nunc, cf. supra.

"Sed hoc potest intelligi tripliciter: uno modo quod ipsa prius duratione exsistens ante a instans in quo causat, potest libere et contingenter causare vel non causare in a; et iste intellectus est verus si voluntas sic praeexistat. Secundo modo potest intelligi quod in eodem instanti in quo causat sit verum dicere quod non causat; et iste intellectus non est possibilis propter contradictoria quae sequuntur, scilicet quod causat in a et non causat in $a$. Tertio modo potest intelligi 'contingenter causare in a', quia libere sine omni variatione et mutatione adveniente sibi vel alteri causae, et sine cessatione alterius causae potest cessare in alio instanti post $a$ ab actu suo, ita quod in a intanti sit haec vera 'voluntas causat', et in alio intanti post a sit haec vera 'voluntas non causat'; et sic voluntas contingenter causat in a, non sic autem naturalis causa contingenter causat" (Op. cit., q. III, p. 536/21).

DANTE, "Monarchia" in Tutte le Opere. A cura di L. Blasucci. Firenzi, Sansoni, 1965, III, XV, p. 316.

Id., op. cit., II, VII; p. 281 ss.

Cf. GLSON, E., Dante et la philosophie. Paris, Vrin, 1939; p. 301.

42 "Sed quando et qualiter cepit esse verum imperium fateor me nescire" Breviloquium, IV, c. 12, p. 120/147 (cito a paginação da edição Baudry seguida da tradução de De Boni: Brevilóquio sobre o Principado Tirânico. Trad. L. A. de Boni. Petrópolis: Vozes, 1988). 
do muito, pode indicar "os modos pelos quais era possível tornar-se verdadeiro império": por submissão voluntária dos homens livres, por guerra justa (de defesa ou por reparação) e por "verdadeira ordenação divina especial". ${ }^{43}$

Quando se trata de mostrar que o "poder esteve no princípio e de modo principal no povo", que depois o transferiu ao imperador; que os povos - "os romanos por exemplo e outros" - transferiram o poder de instituir leis, às vezes para os reis ou ainda a outros de menos poder e dignidade, nestes casos a demonstração se faz não só "pelas histórias e pelas crônicas", mas também pelas Escrituras. ${ }^{44}$ Ora, as Escrituras nada dizem acerca de como e quando o Império Romano veio a ser verdadeiro império; restam, portanto, "as histórias e as crônicas", isto é, o âmbito da contingência. O silêncio das Escrituras, ao contrário do que entendia Dante, não pode ser suprido por qualquer outra forma de desvelamento dos desígnios divinos, como seria o caso da guerra enquanto ordálio.

Bem mais que isso, se o império vem a ser, de modo próprio, pela vontade de homens livres, não depende da vontade divina.

43 "Propter quod solummodo narrabo modos quibus poterat fieri verum imperium,[...]. Quorum unus poterat esse absque omni violentia per consensum liberum et spontaneum populorum voluntarie subdencium se romanis. [...]. Alius modus constituendi verum imperium poterat esse per bellum justum, [...]. Tertio modo poterat constitui romanum imperium per ordinationem specialem divinam, speciali miraculo revelatam, [...]" (Op. cit., IV, c. 10, p. 120/147).

"[...] primo sciendum quod potestas condendi leges et jura humana primo et principaliter fuit apud populum. Unde et populus potestatem condendi leges transtulit in imperatorem. Sic etiam populos, tam romanus videlicet quam alii, potestatem condendi leges transtulerunt in alios et quamdoque in reges, quamdoque in alios minoris et inferioris dignitatis et potestatis. Ista non solum per hystorias et cronicas, sed etiam partim per divina scriptura possent ostendi" (Op. cit., IV, c. 14, p. 96/121). 